Railway Engineering

Jan. 2021

Issue:13, Page: $65-75$

Research Article

doi: 10.47072/demiryolu.796392

http://dergipark.org.tr/demiryolu

e-ISSN: 2687-2463, ISSN: 2149-1607

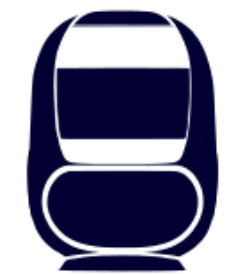

\title{
Türkiye Şartlarına Uygun Vagon Seyir Direnci Formülünün Enerji Verimliliği Açısından Deneysel Olarak Belirlenmesi
}

\author{
Ömür AKBAYIR ${ }^{1} \odot$, Beytullah BAŞEĞMEZ ${ }^{* 2}$ (๑) \\ ${ }^{1}$ Eskişehir Teknik Üniversitesi, Ulaştırma Meslek Yüksekokulu, Raylı Sistemler Makine \\ Teknolojisi Programı, Eskişehir, Türkiye \\ ${ }^{2}$ Uşak Üniversitesi, Teknik Bilimler Meslek Yüksekokulu, Makine Programı, Uşak, Türkiye \\ *beytullah.basegmez@usak.edu.tr
}

(Alınış/Received: 17.09.2020, Kabul/Accepted: 10.12.2020, Yayımlama/Published: 31.01.2021)

Öz: Demiryolu taşıtının enerji sarfiyatına neden olan temel etken, tren hareketini negatif yönde etkileyen kuvvetler toplamı olan tren dirençleridir. Çeşitli çalışma koşullarında ortaya çıkan tren direncinin bilinmesi; ihtiyaç duyulan lokomotif çekiş kuvvetinin hesaplanması, lokomotifin güç gereksiniminin belirlenmesi, enerji tüketimi öngörüsü ve seyir süresinin belirlenmesi çalışmalarında kullanılmaktadır. Birçok ülke, sahip oldukları demiryollarında işletim sırasında ortaya çıkan seyir direncini hesaplamak için kendi formüllerini geliştirmiştir. Türkiye koşullarına en uygun vagon seyir direnci formülünün tespit edilmesi amacını taşıan çalışmada, Türkiye demiryolları 12 farklı hat kesiminde gerçekleştirilen deneylere ilişkin veriler, bu deneyde kullanılan trenlerin özellikleri ve deneylerin uygulandığı demiryolu şartları, 24 adet vagon seyir direnci formülüne uygulanmıştır. Gerçekleştirilen hesaplamalar neticesinde ortaya çıkan tren direnci sonuçları deneysel sonuçlarla karşılaş̧tırılmıştır. Karşılaştırmada ortaya çıkan farkların ortalamaları, çeşitli tren direnci formüllerine göre \%3 ila \%12 arasında değişmektedir. Buradan hareketle, denklem 22'nin en düşük sapmaya sahip olduğu belirlenmiştir. Bu formül, Türkiye demiryollarına en uygun vagon seyir direnci formülü olarak önerilmektedir.

Anahtar kelimeler: Enerji, Tren Direnci, Vagon Seyir Direnci

\section{Experimental Determination of Wagon Running Resistance Formula in terms of Energy Efficiency for Turkish Railway Conditions}

\begin{abstract}
The main factor causing the energy consumption of railway vehicle is train resistances that is the sum of the forces negatively affecting movement of the train. Knowing of the train resistances occurring in the various operating conditions is used for calculating desired locomotive tractive effort, identifying locomotive power requirement, prescience of the energy consumption and determining running time. Formulas are developed by many countries, for calculating of the running resistance that occurs during operating in the own railroads. This study has been undertaken to determine suitable train wagon running resistance formulas for the railroads in Turkey. The experimental data have been recorded over 12 line segments of the national railroad system. The characteristics of the railroad and the rolling stock sets are used to calculate the train resistance according to 24 wagon running resistance formulas. Actual measurements and calculated train resistances are compared. The averages of the differences between the calculated values and the measured values range from $3 \%$ to $12 \%$. The formula that provides the smallest average difference is the equation 22. This formula has been recommended for the Turkish railroads wagon running resistance.
\end{abstract}

Keywords: Energy, Train Resistance, Wagon Running Resistance

\section{Giriş}

Taşımacılıkta tüketilen enerji, Eurostat [1] verilerine göre AB ülkeleri toplam enerji tüketiminin \%31'ini oluşturmaktadır. Sürdürülebilirlik ve çevresel kaygılar, enerji tüketiminin azaltılması

Atıf için/Cite as: Ö. Akbayır, B. Başeğmez, "Türkiye şartlarına uygun vagon seyir direnci formülünün enerji verimliliği açısından deneysel olarak belirlenmesi," Demiryolu Mühendisliği, no. 13, pp. 65-75, Jan. 20221. doi: 10.47072/demiryolu.796392 
yönünde artan baskı oluşturmaktadır. Raylı sistemlerde harcanan enerjinin asgari seviyede tutulması da bu bağlamdadır.

Türkiye'de taşımacılık sektörü sürekli büyümektedir ve raylı sistemlerdeki büyümenin sektördeki büyümeden daha fazla olması amaçlanmaktadır. Raylı sistemlerin yük taşımacılığı içerisindeki oranının artırılması hedeflenmektedir. Artan demiryolu yük taşımacıllı̆g 1 ile birlikte oluşacak enerji sarfiyatının minimize edilmesi, gelişmişlik düzeyinin artışıyla paralel enerji talebi hızla katlanan ve elektrik üretiminin önemli bir kısmı ithal kaynak kullanımına dayanan Türkiye'de, kaynakların verimli kullanılması açısından yüksek öneme sahiptir.

Demiryolu taşıtı çekiş sisteminin enerji sarfiyatına neden olan temel etken, tren dirençleridir. Tren hareketini negatif yönde etkileyen kuvvetler toplamı, tren direnci olarak adlandırılmaktadır. Tren dirençleri; eğimin neden olduğu eğim direnci, hattaki kurblarda ortaya çıkan kurb direnci ve trenin salt seyahati sırasında meydana gelen seyir direnci olmak üzere üç ana başlık altında toplanabilir. Seyir direnci; yuvarlanma direnci, aerodinamik direnç, hattan kaynaklı dirençler ve muylu direncinin toplamını ifade eder.

Tren dirençlerinin belirlenmesi amacıyla uygulanan yöntemler; çekiş gücü yöntemi, dinamometre yöntemi ve salıverme yöntemi olmak üzere üç ana grup altında sınıflandırılabilir. Tren direnci formülleri, bu yöntemlerden biri kullanılarak geliştirilen ampirik fonksiyonlardır. Gerçek şartlarda yapılan birçok test sonucu elde edilen verilerden, en küçük kareler yöntemi ile regresyon analizi yapılarak bir fonksiyon oluşturulmaktadır. Birçok ülke, sahip oldukları demiryollarında işletim sırasında ortaya çıkan tren direncini hesaplamak için kendi formüllerini geliştirmiştir. $\mathrm{Bu}$ çalışma, Türkiye demiryolları tren direnci formülü olarak kullanılacak formülün belirlenmesi amacını taşımaktadır.

\section{Literatürdeki Vagon Seyir Direnci Formülleri}

Schmidt [2] tarafindan 1908-1909 yıllarında Illinois/ABD'de $40 \mathrm{mph}(64 \mathrm{~km} / \mathrm{h})$ hiza kadar yapılan bir dizi deney sonucunda yılında geliştirilen seyir direnci formülü Denklem 1'de yer almaktadır. Denklem 1'de, $R^{\prime}$ seyir direnci (p/t), $W$ araç ağırlığı(t), $V$ hızdır.

$$
R^{\prime}=(V+39,6-0,031 . W) / 4,08+0,152 . W
$$

Yük vagonları için Davis'in [3] geliştirdiği denklem;

$$
R^{\prime}=1,3+29 / w+0,045 \cdot V+\left(0,0005 \cdot A_{f} \cdot V^{2}\right) /(w \cdot n)
$$

Denklem 2'de; $R^{\prime}$ seyir direncidir (lb/ton), $w$ her bir akstaki ağırlıktır (ton), $n$ aks sayısıdır, $A_{f}$ aracın ön alın yüzünün alanıdır (sq.ft), $V$ hızdır (mph)

Schmidt ve Davis formülleri, yayın yılları göz önünde bulundurularak hesaplamaya katılmamıştır. 1940'lar ve 1950'lerde yapılan seyir direnci testleri sonucu, aşağıdaki 'Değiş̧tirilmiş Davis Formülü' kullanılmaya başlanmıştır.

$$
R^{\prime}=0,6+20 / w+0,01 \cdot V+K \cdot V^{2} / w \cdot n
$$

Denklem 3'de; $R^{\prime}$ vagon seyir direnci (lb/t), $w$ aks başına ağırlık (t), $n$ aks sayısı, $V$ hız (mph), $K$ hava direnç katsayısıdır. ( $K$; konvansiyonel taşıtlar için 0,076 , yük kamyonuyla yüklü taşıtlar için 0,16, konteynerler için 0,0935'dir) [4]. Yapılan hesaplamalarda konvansiyonel taşıtlara ait değer kullanılmıştır. 
Lukaszewicz [5] tarafindan İsveç'te 1995 yılında yapılan tam ölçekli testler sonucu çeşitli tipte yük vagonları için seyir direnci formülleri geliştirilmiştir. Denklem 4'de karışık yük vagonları için uygulanan formül verilmiştir. Denklemde, $m_{a}$ aks yüküdür, $n$ toplam aks sayısıdır, $L_{T}$ tren uzunluğudur.

$$
R^{\prime}=\left[n \cdot\left(65+0,6 \cdot 10^{-3} \cdot m_{a}\right)+\left(-22+0,6 \cdot L_{T}\right) \cdot V+\left(5,1+8,1 \cdot 10^{-2} \cdot L_{T}\right) \cdot V^{2}\right] / m
$$

Fransa'nın standart UIC (Uluslararası Demiryolları Birliği) araçları için kullandığı seyir direnci formülü Denklem 5'de verilmiştir [6].

$$
R^{\prime}=1,25+V^{2} / 6300
$$

Cole'un [6] çalışmasında yer verdiği, Fransa'nın 10 ton dingil yüklü vagonlar için kullandığı seyir direnci formülü Denklem 6'da verilmiştir

$$
R^{\prime}=1,5+V^{2} / 1600
$$

Denklem 5 ve 6' da; $R^{\prime}$ seyir direncidir (daN/t), $V$ ise $(\mathrm{km} / \mathrm{h})$ cinsinden hızdır.

Fransa Demiryolları'nın (SNCF) 18 ton dingil yüklü dolu yük vagonları için kullandığı seyir direnci formülü Denklem 7'de verilmiştir [6]. Denklemde; $R^{\prime}$ seyir direncidir (daN/t), $V$ hızdır $(\mathrm{km} / \mathrm{h})$.

$$
R^{\prime}=1,2+V^{2} / 4000
$$

SNCF'nin ağır yük trenleri için kullandığg seyir direnci formülü Denklem 8' de yer almaktadır [7]. Denklemde; $R^{\prime}$ seyir direncidir (daN/t), $V$ hızdır $(\mathrm{km} / \mathrm{h})$.

$$
R^{\prime}=1+V^{2} / 4000
$$

Yük trenleri için Rusya'da kayda alınan seyir direnci formülü Denklem 9'da verilmiştir [7].

$$
R^{\prime}=0,7+\left(3+0,1 \cdot V+0,0025 \cdot V^{2}\right)
$$

DB'nin (Deutsche Bahn) dolu yük trenleri için kullandığı seyir direnci formülü Denklem 10'da verilmiştir [8]. Denklem 10'da; $R^{\prime}$ seyir direncidir (daN/t), $V$ hızdır $(\mathrm{km} / \mathrm{h})$.

$$
R^{\prime}=1+0,1 \cdot 0,2 \cdot(V / 10)^{2}
$$

Cole'un [6] çalışmasında yer alan Amerikan Demiryolları tarafından kullanılan değiştirilmiş Davis formülü;

$$
R^{\prime}=K_{a} \cdot\left[2,943+89,2 / m_{a}+0,0306 \cdot V+1,741 \cdot k_{a d} \cdot V^{2} / m_{a} \cdot n\right]
$$

Denklem 11'de, seyir direnci N/t, $V$ hız $(\mathrm{km} / \mathrm{h}), m_{a}$ aks başına kütle $(\mathrm{t}), n$, aks sayısıdır. Konteynerli platform vagonu için $K_{a}=0,95$, treylerli platform vagonu için $K_{a}=1,05$, kapalı dipten kapaklı vagon için $K_{a}=1,05$, sırasıyla boş, dolu kapalı ve boş açık otomobil vagonları için $K_{a}=1,2, K_{a}=1,3, K_{a}=1,9^{\prime}$ dur. $k_{a d}$, konvansiyonel taşitlar için 0,07 , konteynerler için 0,0935 , treyler ve platform vagonlar için 0,16 'dır. Sonuçları sunulan hesaplamalarda $K_{a}=1,05$ ve $k_{a d}=0,07$ alınmışır. 
Alman demiryollarında yük trenleri için kullanılan Strahl formülü aşağıda verilmiştir [9]. Denklem 12 'de $R^{\prime}$ seyir direncidir (N/kg), $V$ hızdır $(\mathrm{m} / \mathrm{s})$. Formüldeki $m$ 'in değeri yük vagonları için 10 'dur.

$$
R^{\prime}=0,01\left[(1,5-2,5)+\left(0,007+\frac{1}{m}\right)\left(\frac{3.6 V}{10}\right)^{2}\right]
$$

Surbistan ve Karadağ'da çeşitli tipteki yük vagonları için değiştirilmiş Strahl formülleri kullanılmaktadır [7]. Aşağıda sırasıyla rulmanlı yatağa sahip (Denklem 13) ve kaymalı yataklı (Denklem 14) karış1k vagonlardan oluşan yük trenleri için kullanılan formüller verilmiştir. Denklem 13 ve 14 'de $R^{\prime}$ seyir direncidir (daN/t), $V$ hızdır (km/h).

$$
\begin{gathered}
R^{\prime}=2,2-80 /(V+38)+(\mathrm{k}+0,007) \cdot(V / 10)^{2} ; \mathrm{k}=0,050 \\
R^{\prime}=2+(k+0,007) \cdot(v / 10)^{2} ; k=0,050
\end{gathered}
$$

Çek Cumhuriyeti'nin dolu yük trenleri için kullandığı seyir direnci formülü;

$$
R^{\prime}=1,3+0,00015 \cdot V^{2}
$$

Denklem 15'de; $R^{\prime}$ seyir direncidir (daN/t), $V$ hızdır $(\mathrm{km} / \mathrm{h})[7]$.

Radosavljevic [7] tarafından karışık yük vagonları için Sırbistan, Hırvatistan hatlarında 2000 yılında yapılan testler sonucu geliştirilen seyir direnci formülü aşağıdadır. Denklem 16 'da; $R^{\prime}$ seyir direncidir (daN/t), $V$ hızdır $(\mathrm{km} / \mathrm{h})$.

$$
R^{\prime}=0,483+0,0183 \cdot V+0,0001 \cdot V^{2}
$$

Yük vagonları için AAR tarafından yayınlanmış değiştirilmiş Davis formülü verilmiştir [10]. Denklem 17'de; $R^{\prime}$ seyir direncidir (N/t), $V$ hızdır (km/h), $w$ her bir akstaki ağırlıktır (ton), $n$ aks sayısidir.

$$
R^{\prime}=6,5+320 / w \cdot n+0,46 \cdot V+0,096 \cdot V^{2} / w \cdot n
$$

Çin ulusal demiryollarının rulmanlı yatağa sahip dolu vagonlar için kullandığı seyir direnci formülü Denklem 18'de verilmiştir [8]. Denklemde; direnç daN/t, hız km/h cinsindendir

$$
R^{\prime}=0,92+0,0048 \cdot V+0,000125 \cdot V^{2}
$$

Çin ulusal demiryollarının kaymalı yatağa sahip vagonlar için kullandığı seyir direnci formülü Denklem 19'da verilmiştir [8]. Denklemde; $R^{\prime}$ seyir direncidir (daN/t), $V$ hızdır (km/h).

$$
R^{\prime}=1,07+0,0011 \cdot V+0,000236 \cdot V^{2}
$$

Koffman tarafından geliştirilen yük vagonları için seyir direnci formülü, Denklem 20'de verilmiştir [8]. Denklem 20'de, $R^{\prime}$ seyir direncidir (daN/t), $V$ hızdır $(\mathrm{km} / \mathrm{h}), m_{a}$ aks yüküdür (ton).

$$
R^{\prime}=0,7+\left(8+0,1 \cdot V+0,0025 \cdot V^{2}\right) / m_{a}
$$

Avustralya'da dolu vagonlar için kullanılan seyir direnci formülü, Denklem 21'de yer almaktadır [8]. Denklemde; $R^{\prime}$ seyir direncidir $(\mathrm{N} / \mathrm{t}), V$ hızdır $(\mathrm{km} / \mathrm{h})$. 


$$
R^{\prime}=5,17+0,010997 \cdot V+0,00051 \cdot V^{2}
$$

Daha kısa zamanda uygulanabilen ve diğer yöntemlerle eşdeğer sonuçların elde edilebildiği, Milano Politeknik Üniversitesi'nden Somaschini, Rocchi, Tomasini ve Schito'nun [11] ortaya koyduğu yeni regresyon yöntemiyle elde edilmiş seyir direnci formülü aşağıda yer almaktadır. Denklem 22'de, $R^{\prime}$ seyir direncidir $(\mathrm{N})$, m tren toplam kütlesi (t) ve $V$ hızdır (m/s).

$$
R^{\prime}=5,138 \cdot m+21,91 \cdot V+6,21 \cdot V^{2}
$$

Hızı $100 \mathrm{~km} / \mathrm{h}$ olan ve tamamı aynı tip kapalı vagonlardan oluşan yük trenleri için Fransız Demiryollarının (SNCF) kullandığı seyir direnci formülü Denklem 23'de verilmiştir [12]. Denklemde; $R^{\prime}$ seyir direncidir (kp/ton), $V$ hızdır $(\mathrm{km} / \mathrm{h})$.

$$
R^{\prime}=1,5+V^{2} / 4200
$$

Yükü ve darası toplamı 80 ton olan spesifik vagonlar (kömür, cevher, boraks vb.) için Fransız Demiryollarının (SNCF) kullandığı seyir direnci formülü, Denklem 24'tedir. [12]. Denklemde; $R^{\prime}$ seyir direncidir (kp/ton), $V$ hızdır $(\mathrm{km} / \mathrm{h})$.

$$
R^{\prime}=1,2+V^{2} / 4500
$$

DB'nin yük vagonları için kullandığı seyir direnci formülü Denklem 25'de verilmiştir [12]. Denklemde; $R^{\prime}$ seyir direncidir (kp/ton), $V$ hızdır (km/h).

$$
R^{\prime}=1,5+V^{2} / 1200
$$

E tipi yüksek kenarlı açık vagonlardan oluşan trenler için geliştirilmiş seyir direnci formülü Denklem 26'da verilmişsir [13]. Denklem 26'da $R^{\prime}$ seyir direncidir (kg/ton), $V$ hızdır (km/h).

$$
R^{\prime}=1,333973+0,021983 \cdot V+0,000242 \cdot V^{2}
$$

\section{Metot}

En uygun vagon seyir direncinin tespiti amacıyla, Türkiye demiryollarında gerçekleştirilen deney verileri çeşitli ülkeler/kuruluşlar tarafından kullanılmakta olan formüllere uygulanmıştır. Hesaplamalarda, TCDD (Türkiye Cumhuriyeti Devlet Demiryolları) Kapasite Yönetim Daire Başkanlığının 3. ve 7. bölgelerde, 2017 yılında gerçekleştirilen deney verileri kullanılmıştır. Şekil 1'de bir test treni görülmektedir. Deneylerde karışık yük vagonları kullanılmıştır.

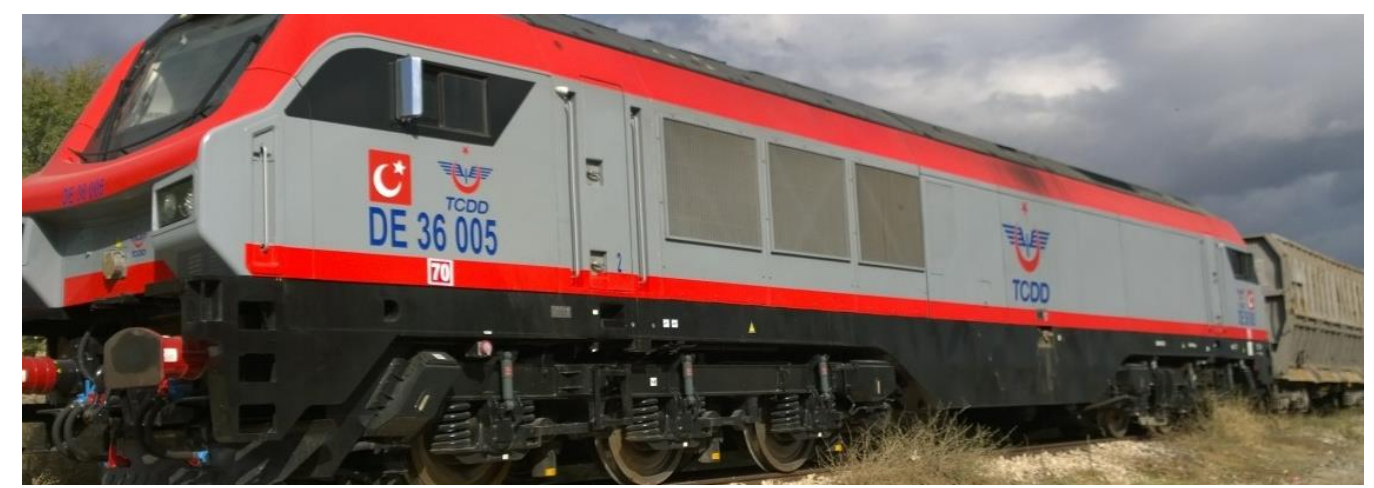

Şekil 1. Teste kullanılan DE 36005 lokomotif 
Yapılan hesaplamalarda formüllere girilen deney verileri, Tablo 1'de yer almaktadır. Tekerlek kuvveti verileri Şekil 2'de görülen lokomotifin kumanda masasında bulunan akıllı ekran üzerinden temin edilmiştir. Tablo 1'de deneylerin gerçekleştiği hat kesimlerine ait rampa, kurb değerleri ve kritik mesafeler verilmiştir. Deneylerde kullanılan lokomotif tipleri, bu lokomotiflerin kütleleri ve kritik hız değerleri, ayrıca trenin toplam kütlesi ve hat kesimi içerisinde ulaşılan maksimum hız değerleri Tablo 1'de yer almaktadır. Giriş bölümünde verilen denklemler yardımıyla hesaplanan toplam dirençler ile karşılaştırmada kullanılan, cer akım kuvveti değerleri, her bir hat kesimi için Tablo 1'e eklenmiştir.

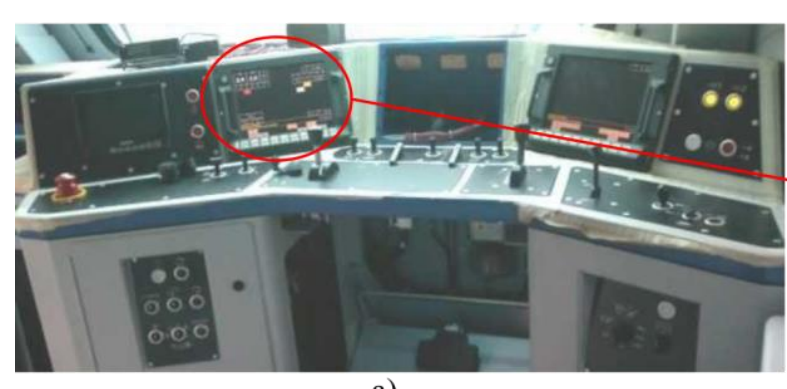

a)
Cer motorlarının çektiği akıma dayalı çekme/cer/ tekerlek kuvveti $(\mathrm{kN})$

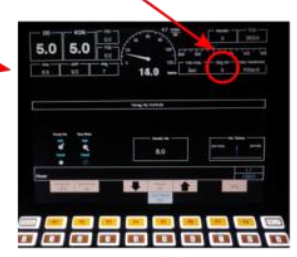

b)

Şekil 2. a) DE 36000 tipi lokomotifi kumanda masası b) kumanda masası üzerinde bulunan akıllı ekran

Tablo 1. Deney verileri ve deney yapılan hat kesimlerinin karakteristikleri

\begin{tabular}{|c|c|c|c|c|c|c|c|c|c|}
\hline $\begin{array}{c}\text { Hat } \\
\text { Kesimleri }\end{array}$ & Rampa & $\begin{array}{c}\text { Kurb } \\
(\mathrm{m})\end{array}$ & $\begin{array}{l}\text { Tren } \\
\text { Ton }\end{array}$ & $\begin{array}{l}\text { Loko } \\
\text { ton }\end{array}$ & $\begin{array}{c}\text { Loko } \\
\text { no }\end{array}$ & $\begin{array}{c}\text { Kritik } \\
\text { mesafe } \\
(\mathrm{km}+\mathrm{m})\end{array}$ & $\begin{array}{c}\text { Kritik } \\
\text { h1z } \\
(\mathrm{km} / \mathrm{h})\end{array}$ & $\begin{array}{c}\text { Kesim } \\
\text { sonunda } \\
\text { h1z } \\
(\mathrm{km} / \mathrm{h})\end{array}$ & $\begin{array}{c}\text { Cer } \\
\text { kuvveti } \\
(\mathrm{kN})\end{array}$ \\
\hline $\begin{array}{l}\text { Banaz- } \\
\text { Nohutova }\end{array}$ & 17,19 & 299 & 1586 & 129 & $\begin{array}{c}\mathrm{DE} \\
36020\end{array}$ & $316+300$ & 23 & 25 & 328 \\
\hline $\begin{array}{l}\text { Ekinova- } \\
\text { Karakuyu }\end{array}$ & 14,41 & 390 & 1700 & 129 & $\begin{array}{c}\mathrm{DE} \\
36002\end{array}$ & $90+800$ & 23 & 30 & 315 \\
\hline $\begin{array}{l}\text { Kütahya- } \\
\text { Demirciören }\end{array}$ & 9,93 & 368 & 2547 & 129 & $\begin{array}{c}\mathrm{DE} \\
36005\end{array}$ & $21+000$ & 23 & 27 & 320 \\
\hline $\begin{array}{l}\text { Piribeyler- } \\
\text { Gazellidere }\end{array}$ & 13,97 & 246 & 1751 & 129 & $\begin{array}{c}\mathrm{DE} \\
36021\end{array}$ & $188+200$ & 23 & 26 & 310 \\
\hline $\begin{array}{l}\text { Tavşanl1- } \\
\text { Güzelyurt }\end{array}$ & 14,18 & 294 & 1703 & 129 & $\begin{array}{c}\text { DE } \\
36020\end{array}$ & $46+100$ & 23 & 26 & 300 \\
\hline $\begin{array}{l}\text { Tinaztepe- } \\
\text { Kocatepe }\end{array}$ & 18,90 & 292 & 1399 & 129 & $\begin{array}{c}\mathrm{DE} \\
36005\end{array}$ & $32+950$ & 23 & 28 & 300 \\
\hline $\begin{array}{l}\text { Oturak- } \\
\text { Dumlupınar }\end{array}$ & 25,09 & 286 & 1070 & 129 & $\begin{array}{c}\mathrm{DE} \\
36001\end{array}$ & $350+100$ & 23 & 24 & 280 \\
\hline $\begin{array}{l}\text { Kaklık- } \\
\text { Bozkurt }\end{array}$ & 19,95 & 400 & 1416 & 129 & $\begin{array}{c}\mathrm{DE} \\
36011\end{array}$ & $287+650$ & 23 & 27 & 304 \\
\hline $\begin{array}{l}\text { Güzelyurt- } \\
\text { Köprüören }\end{array}$ & 14,41 & 288 & 1383 & 88 & $\begin{array}{c}E \\
68041\end{array}$ & $40+200$ & 31 & 33 & 240 \\
\hline $\begin{array}{l}\text { Kay1- } \\
\text { Güzelyurt }\end{array}$ & 14,17 & 294 & 1383 & 88 & $\begin{array}{c}\mathrm{E} \\
68041\end{array}$ & $47+600$ & 31 & 43 & 240 \\
\hline $\begin{array}{l}\text { Dinar- } \\
\text { Karakuyu }\end{array}$ & 20,04 & 300 & 1300 & 129 & $\begin{array}{c}\mathrm{DE} \\
36011\end{array}$ & $381+900$ & 23 & 30 & 278 \\
\hline $\begin{array}{l}\text { İhsaniye- } \\
\text { Döğer }\end{array}$ & 12,97 & 296 & 2024 & 129 & $\begin{array}{c}\mathrm{DE} \\
36003\end{array}$ & $119+200$ & 23 & 27 & 309 \\
\hline
\end{tabular}

Her bir hat kesimi için deney verilerinden yola çıkılarak kurb ve eğim dirençleri ile bunların toplamından ibaret olan eşdeğer direnç değerleri hesaplanmıştır. Ayrıca ivmelenme ve lokomotif seyir dirençleri de hesaplanarak eklenmiştir. Bu direnç değerleri için birer formül üzerinden 
hesaplama gerçekleştirilmiştir. Kurp direnci formülü olarak kullanılan Denklem 27'de $R_{c}$ kurb direnci (kp/t) ve $R$ kurp yarıçapıdır (m) [12].

$$
R_{c}=\frac{800}{R}
$$

Eğim direnci formülü olarak kullanılan Denklem 28'de $R_{g}$ eğim direnci $(\mathrm{kp} / \mathrm{t})$ ve $i$ eğim değeridir (1000 metrede yükseklik (m)) [12].

$$
R_{g}=i
$$

İvmelenme direnci formülü olarak, Denklem 29 kullanılmıştır. Burada, $R_{a} \mathrm{~N} / \mathrm{t}, V \mathrm{~km} / \mathrm{h}$ ve $t$ saniye cinsindendir.

$$
R_{a}=\frac{1000}{3,6} \frac{V_{2}-V_{1}}{t}
$$

Lokomotif seyir direnci değerleri ise Denklem 30 yardımıyla hesaplanmıştır. Burada, $R_{L}$ lokomotif seyir direnci $(\mathrm{kp} / \mathrm{t}) G_{L}$ lokomotif kütlesi (t), $n$ aks sayısı, $A$ ön yüzey alanı $\left(\mathrm{m}^{2}\right)-10$ alınmıştır- ve $V \mathrm{~km} / \mathrm{h}$ cinsinden hızdır [12].

$$
R_{L}=0,65 \cdot G_{L}+13,15 \cdot n+0,00932 \cdot G_{L} \cdot V+0,004526 \cdot A \cdot V^{2}
$$

Türkiye şartlarına uygun formülü ortaya çıkarılmak istenen vagon seyir dirençleri ise ayrıntılı olarak incelenmiştir. Hat kesimlerinin her birine ait veri kullanılarak giriş bölümünde sunulan formüllerle hesaplamalar gerçekleştirilmiştir. Her bir hat kesiminde denklem 27 ila 30 arasında verilen formüllerle hesaplanan direnç değerleri ile vagon seyir direnci formülleriyle hesaplanan direnç değerleri toplanmıştır. Tüm direnç türlerindeki birimler $\mathrm{kN}$ cinsine çevrilerek denklem 31'e göre toplam dirençler hesaplanmıştır.

$$
R_{T}=R_{c}+R_{g}+R_{a}+R_{L}+R^{\prime}
$$

Yapılan hesaplamaların sonuçları ile deneylerde okunan, çekilen elektrik akımı değerleri karşılaştırılmıştır. Hesaplamalar sonucu elde edilen toplam direnç değerleri ile lokomotifin çektiği cer kuvveti değerleri arasındaki yüzde fark değerleri incelenerek en düşük sapmaya sahip formülü belirlemek, çalışmada uygun vagon seyir direnci formülünü seçmek için kullanılan yöntemdir.

\section{Bulgular}

Tablo 2'de her bir hat kesimi için 24 adet tren direnci formülüne göre toplam direnç değerleri yer almaktadır. Tablo 2'de belirtilen toplam direnç değerleri, Metot bölümünde belirtilen diğer dirençler ile belirtilen numaralı denklem yardımıyla hesaplanan vagon seyir direncinin toplamını ifade etmektedir.

Güzelyurt-Köprüören, Kay1-Güzelyurt, Dinar-Karakuyu ve İhsaniye-Döğer hatlarında gerçekleştirilen deneylerin verileriyle de hesaplama yapılmıştır. Ancak bu hat kesimlerinde cer kuvveti değeri ile kullanılan denklemler yardımıyla hesaplanan toplam direnç değerleri arasındaki farkların ortalamaları \% 13 ila 20 gibi yüksek değerlerde çıkmıştır. Bu sebeple bu hat kesimleri için elde edilen sonuçlar, sunulmamıştır. 
Tablo 2. Çeşitli tren direnci formüllerine göre hat kesimlerinde toplam dirençler $(\mathrm{kN})$

\begin{tabular}{|c|c|c|c|c|c|c|c|c|}
\hline 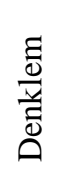 & 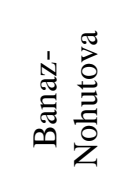 & 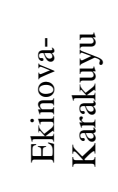 & 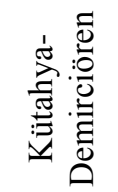 & 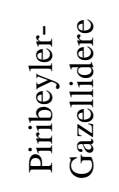 & 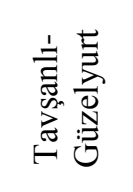 & 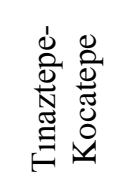 & 䮍壳 & 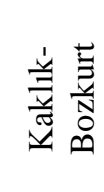 \\
\hline 3 & 20207 & 310,09 & 334,98 & 20 & 3 & 20,03 & 39 & 50 \\
\hline 4 & 330,88 & 308,40 & 328,52 & 314,26 & 296,15 & 317,35 & 05,81 & 323,26 \\
\hline 5 & 337,72 & 314,89 & 348,69 & 329,12 & 309,27 & 326,69 & 310,07 & 331,64 \\
\hline 6 & 346,31 & 326,28 & 363,71 & 339,02 & 318,90 & 335,30 & 315,62 & 340,00 \\
\hline 7 & 337,84 & 315,44 & 349,11 & 329,32 & 309,47 & 326,99 & 310,09 & 331,88 \\
\hline 8 & 334,66 & 312,04 & 344,01 & 325,82 & 306,06 & 324,20 & 307,95 & 329,04 \\
\hline 9 & 3 & 315,00 & 2,11 & ,03 & 78 & 93 & 09,77 & 329,29 \\
\hline 10 & 334,17 & 311,28 & 343,08 & 325,23 & 305,49 & 65 & 307,65 & 328,53 \\
\hline 11 & 33 & 31 & 34 & 33 & 302,32 & & 09,57 & 327,64 \\
\hline 12 & 35 & 3. & 7 & 28 & 22 & & 36 &, 59 \\
\hline 13 & 336,73 & 317 & 349,17 & 328,73 & 308,90 & 327,54 & 308,96 & 31,91 \\
\hline 14 & 353,70 & 333,94 & 375,42 & 347,12 & 326,78 & 341,70 & 320,63 & 346,51 \\
\hline 15 & 338,43 & 315,61 & 349,80 & 329,89 & 310,02 & 327,30 & 310,55 & 332,26 \\
\hline 16 & 332,23 & 310,29 & 340,64 & 323,33 & 303,63 & 322,49 & 306,20 & 327,17 \\
\hline 17 & 345,25 & 326,13 & 362,48 & 338,06 & 317,98 & 334,97 & 314,86 & 339,48 \\
\hline 18 & 334,06 & 311,22 & 342,95 & 325,13 & 305,39 & 323,59 & 307,56 & 328,46 \\
\hline 19 & 336,07 & 313,58 & 346,29 & 327,38 & 307,58 & 325,45 & 308,90 & 330,31 \\
\hline 20 & 344,56 & 322,20 & 349,01 & 328,43 & 309,38 & 328,23 & 314,57 & 333,99 \\
\hline 21 & 325,47 & 301,35 & 328,77 & 315,51 & 296,03 & 315,69 & 301,84 & 320,57 \\
\hline 22 & 324,93 & 300,56 & 327,50 & 314,83 & 295,39 & 315,20 & 301,63 & 320,09 \\
\hline 23 & 341,97 & 319,80 & 355,70 & 333,87 & 313,89 & 330,60 & 312,89 & 335,54 \\
\hline 24 & 337,15 & 314,56 & 347,92 & 328,54 & 308,70 & 326,32 & 309,65 & 331,22 \\
\hline 25 & 347,76 & 328,73 & 366,54 & 340,78 & 320,61 & 337,01 & 316,49 & 341,57 \\
\hline 26 & 347,98 & 328,09 & 366,47 & 340,89 & 320,72 & 336,82 & 316,72 & 341,53 \\
\hline
\end{tabular}

Her bir hat kesimi için 24 adet vagon seyir direnci formülü kullanılarak hesaplanan toplam direnç değerlerinin deney sırasında belirlenen cer kuvveti değerlerinden sapmaları, Tablo 3'de yer almaktadır. Her bir vagon seyir direnci formülü için tüm hat kesimlerindeki sapma miktarlarının ortalaması alınmış ve Tablo 3'ün en sağ sütununda sunulmuştur. Çizelgede görüleceği üzere; sapma miktarı en düşük olan formül; Denklem 22'dir, onu sirasıyla Denklem 21 ve Denklem 4 takip etmektedir. 
Tablo 3. Çeşitli tren direnci formüllerinin hat kesimlerinde sapma miktarları ile sapma ortalamaları

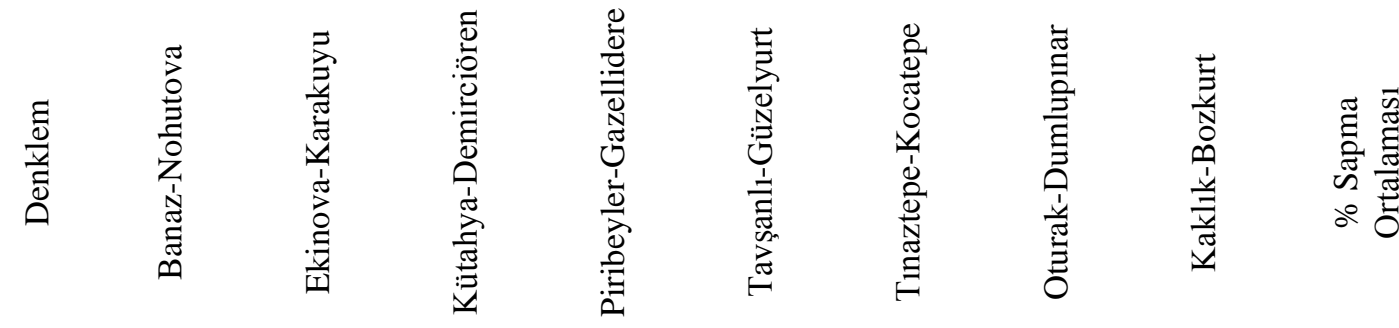

\begin{tabular}{cccccccccc}
\hline 3 & $\% 1,94$ & $\% 1,56$ & $\% 4,68$ & $\% 2,97$ & $\% 0,07$ & $\% 6,68$ & $\% 9,96$ & $\% 7,10$ & $\% 4,37$ \\
4 & $\% 0,88$ & $\% 2,10$ & $\% 2,66$ & $\% 1,37$ & $\% 1,28$ & $\% 5,78$ & $\% 9,22$ & $\% 6,34$ & $\% 3,70$ \\
5 & $\% 2,96$ & $\% 0,03$ & $\% 8,96$ & $\% 6,17$ & $\% 3,09$ & $\% 8,90$ & $\% 10,74$ & $\% 9,09$ & $\% 6,24$ \\
6 & $\% 5,58$ & $\% 3,58$ & $\% 13,66$ & $\% 9,36$ & $\% 6,30$ & $\% 11,77$ & $\% 12,72$ & $\% 11,84$ & $\% 9,35$ \\
7 & $\% 3,00$ & $\% 0,14$ & $\% 9,10$ & $\% 6,23$ & $\% 3,16$ & $\% 9,00$ & $\% 10,75$ & $\% 9,17$ & $\% 6,32$ \\
8 & $\% 2,03$ & $\% 0,94$ & $\% 7,50$ & $\% 5,10$ & $\% 2,02$ & $\% 8,07$ & $\% 9,98$ & $\% 8,24$ & $\% 5,49$ \\
9 & $\% 2,88$ & $\% 0,00$ & $\% 6,91$ & $\% 4,52$ & $\% 1,59$ & $\% 7,98$ & $\% 10,63$ & $\% 8,32$ & $\% 5,35$ \\
10 & $\% 1,88$ & $\% 1,18$ & $\% 7,21$ & $\% 4,91$ & $\% 1,83$ & $\% 7,88$ & $\% 9,87$ & $\% 8,07$ & $\% 5,35$ \\
11 & $\% 2,62$ & $\% 0,72$ & $\% 5,57$ & $\% 3,66$ & $\% 0,77$ & $\% 7,37$ & $\% 10,56$ & $\% 7,78$ & $\% 4,88$ \\
12 & $\% 6,93$ & $\% 5,74$ & $\% 16,24$ & $\% 11,06$ & $\% 8,01$ & $\% 13,39$ & $\% 13,70$ & $\% 13,35$ & $\% 11,05$ \\
13 & $\% 2,66$ & $\% 0,74$ & $\% 9,12$ & $\% 6,04$ & $\% 2,97$ & $\% 9,18$ & $\% 10,34$ & $\% 9,18$ & $\% 6,28$ \\
14 & $\% 7,83$ & $\% 6,01$ & $\% 17,32$ & $\% 11,97$ & $\% 8,93$ & $\% 13,90$ & $\% 14,51$ & $\% 13,98$ & $\% 11,81$ \\
15 & $\% 3,18$ & $\% 0,19$ & $\% 9,31$ & $\% 6,42$ & $\% 3,34$ & $\% 9,10$ & $\% 10,91$ & $\% 9,30$ & $\% 6,47$ \\
16 & $\% 1,29$ & $\% 1,50$ & $\% 6,45$ & $\% 4,30$ & $\% 1,21$ & $\% 7,50$ & $\% 9,36$ & $\% 7,62$ & $\% 4,90$ \\
17 & $\% 5,26$ & $\% 3,53$ & $\% 13,27$ & $\% 9,05$ & $\% 5,99$ & $\% 11,66$ & $\% 12,45$ & $\% 11,67$ & $\% 9,11$ \\
18 & $\% 1,85$ & $\% 1,20$ & $\% 7,17$ & $\% 4,88$ & $\% 1,80$ & $\% 7,86$ & $\% 9,84$ & $\% 8,04$ & $\% 5,33$ \\
19 & $\% 2,46$ & $\% 0,45$ & $\% 8,22$ & $\% 5,61$ & $\% 2,53$ & $\% 8,48$ & $\% 10,32$ & $\% 8,66$ & $\% 5,84$ \\
20 & $\% 5,05$ & $\% 2,28$ & $\% 9,07$ & $\% 5,94$ & $\% 3,13$ & $\% 9,41$ & $\% 12,35$ & $\% 9,86$ & $\% 7,14$ \\
21 & $\% 0,77$ & $\% 4,33$ & $\% 2,74$ & $\% 1,78$ & $\% 1,32$ & $\% 5,23$ & $\% 7,80$ & $\% 5,45$ & $\% 3,68$ \\
22 & $\% 0,94$ & $\% 4,58$ & $\% 2,34$ & $\% 1,56$ & $\% 1,54$ & $\% 5,07$ & $\% 7,73$ & $\% 5,29$ & $\% 3,63$ \\
23 & $\% 4,26$ & $\% 1,52$ & $\% 11,16$ & $\% 7,70$ & $\% 4,63$ & $\% 10,20$ & $\% 11,75$ & $\% 10,38$ & $\% 7,70$ \\
24 & $\% 2,79$ & $\% 0,14$ & $\% 8,73$ & $\% 5,98$ & $\% 2,90$ & $\% 8,77$ & $\% 10,59$ & $\% 8,95$ & $\% 6,11$ \\
25 & $\% 6,02$ & $\% 4,36$ & $\% 14,54$ & $\% 9,93$ & $\% 6,87$ & $\% 12,34$ & $\% 13,03$ & $\% 12,36$ & $\% 9,93$ \\
26 & $\% 6,09$ & $\% 4,16$ & $\% 14,52$ & $\% 9,97$ & $\% 6,91$ & $\% 12,27$ & $\% 13,11$ & $\% 12,35$ & $\% 9,92$ \\
\hline
\end{tabular}

\section{Sonuç}

Tren direnci formülleri, demiryolu taşıtlarının enerji tüketimi verilerinin öngörülmesi, lokomotifin güç gereksiniminin ve çekiş kuvvetinin belirlenmesi ve seyir süresi hesaplamalarında kullanılmaktadır. Bu çalışmada, farklı ülkeler tarafından kullanılan çeşitli vagon seyir direnci formüllerine; Türkiye Cumhuriyeti demiryollarının farklı hatlarında gerçekleştirilen deneylerden elde edilen veriler uygulanmıştır. Her bir hat kesimi için tren dirençleri formülleri ile yapılan hesaplamalar neticesinde Denklem 22'nin demiryollarımızda yapılan deney verileri sonuçları ile sapma miktarının en az olduğu görülmüştür. Buradan hareketle Türkiye demiryollarına en uygun vagon seyir direnci formülünün, $\mathrm{R}^{\prime}=5,138 \cdot \mathrm{m}+21,91 \cdot \mathrm{V}+6,21 \cdot \mathrm{V}^{2}$ olduğu anlaşılmıştır. 
Denklem 21'de verilen $\mathrm{R}^{\prime}=5,17+0,010997 . \mathrm{V}+0,00051 . \mathrm{V}^{2}$ formülü de oldukça yakın sonuçlar verdiğinden yapılacak tren direnci hesaplamalarında kullanılabilecektir. Tren direnci hesaplamalarında önerilen formülün tercih edilmesi ile Türkiye demiryollarının enerji tüketimine ilişkin veriler daha yüksek doğrulukla öngörülecek, enerji tüketimini azaltmaya yönelik yapılacak çalışmalarda kullanılabilecektir. Böylece enerji verimliliği artırılacak, etkin kaynak kullanımına gidilmiş olacaktır. Yük trenlerinin direnç kuvveti daha yükssek doğrulukla hesaplanacağından hatlarda çalıştırılacak lokomotif seçimi daha etkin yapılabilecek, benzer şekilde demiryollarının parametrelerine uyumlu lokomotif tasarımı/üretiminde güç, çekiş kuvveti vd. parametreler belirlenirken faydalanılabilecektir. Önerilen formül, yük trenlerinin maksimum hızının belirlenmesinde kullanılabilecek, yüksek hızlı yük taşımacılı̆̆ 1 gerçekleştirmek amacıyla yapılacak çalışmalarda yararlanılabilecektir.

$\mathrm{Bu}$ çalışmada diğer ülkeler tarafından geliştirilen vagon seyir dirençlerinden Türkiye için en uygunu belirlenmiştir. Vagon seyir direncini belirlenmesi amacıyla uygulanan çekiç gücü yöntemi, dinamometre yöntemi veya salıverme yöntemi ile Türkiye'ye özgü bir ampirik eşitlik geliştirilmesi başka bir çalışma konusu olabilir.

\section{Kaynakça}

[1] Eurostat, "Energy statistics - an overview - Statistics Explained," 2016. [Online]. Available: https://ec.europa.eu/eurostat/statistics-explained/index.php/Energy_statistics__an_overview\#Final_energy_consumption. [Accessed: 16-Sep-2020].

[2] E. C. Schmidt, "Freight Train Resistance. Its Relation to Car Weight.," Vol. 43 Eng. Exp. Stn. Illinois Univ. Urbana, Illinois., 1910.

[3] W. J. Davis, The Tractive Resistance of Electric Locomotives and Cars. Schenectady, N.Y. General Electric, 1926.

[4] AREMA Manual for Railway Engineering, Economics of Railway Engineering and Operation, Train Performance. American Railway Engineering and Maintenance of Way Association, 1999.

[5] P. Lukaszewicz, "Energy Consumption and Running Time for Trains," Royal Institute of Technology, Stockholm, 2001.

[6] S. Iwnicki, Handbook of railway vehicle dynamics. Boca Raton: CRC/Taylor \& Francis, 2006.

[7] A. Radosavljevic, "Measurement of train traction characteristics," Proc. Inst. Mech. Eng. Part F J. Rail Rapid Transit, vol. 220, no. 3, pp. 283-291, May 2006.

[8] C. Newman, "5AT Advanced Steam Locomotive Project Locomotive and Train Resistance," 2010. [Online]. Available: http://5at.co.uk/index.php/definitions/terrms-anddefinitions/resistance.html\#Plots. [Accessed: 17-Sep-2020].

[9] B. P. Rochard and F. Schmid, "A review of methods to measure and calculate train resistances," Proc. Inst. Mech. Eng. Part F J. Rail Rapid Transit, vol. 214, no. 4, pp. 185-199, Jul. 2000.

[10]F. Szanto, "Rolling Resistance Revisited," in CORE2016 Conference on Railway Excellence RTSA, 2016.

[11]C. Somaschini, D. Rocchi, G. Tomasini, and P. Schito, "Simplified Estimation of Train Resistance Parameters: Full Scale Experimental Tests and Analysis," in Proceedings of the Third International Conference on Railway Technology: Research, Deve-lopment and Maintenance, 2016.

[12]C. Urlu, Demiryolu Araçlarının İleri Dinamiği. Ankara: TCDD Yayınları, 1999.

[13]M. K. Jain, "Train, grade, curve and Acceleration Resistance | RailElectrica," 2013. [Online]. Available: https://www.railelectrica.com/traction-mechanics/train-grade-curve-and-accelerationresistance-2/. [Accessed: 16-Sep-2020]. 


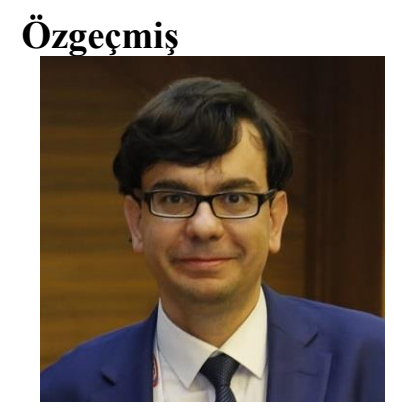

\section{Ömür AKBAYIR}

Lise eğitimini Demiryolu Meslek Lisesinde, Lisans ve Yüksek Lisans Eğitimini Eskişehir Osmangazi Üniversitesinde, Doktora eğitimini Gazi Üniversitesinde tamamlamıştır. 15 yıl TCDD'nin çeşitli işyerlerinde çeşitli görevlerde bulunmuş olup, 2015 yılından beri Eskişehir Teknik Üniversitesinde Dr. Öğr. Üyesi olarak çalışmaktadır.

E-Posta: omurakbayir@eskisehir.edu.tr

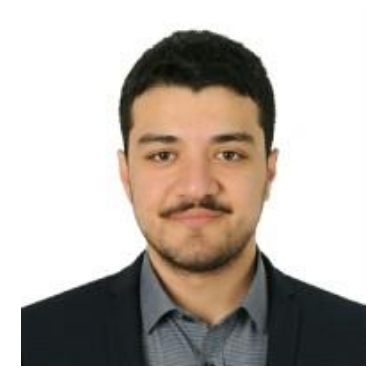

\section{Beytullah BAŞEĞMEZ}

1994 Eskişehir doğumludur. Marmara Üniversitesi Makine Mühendisliği bölümünden 2016 y1lında mezun oldu. 2018'de Eskişehir Osmangazi Üniversitesi Raylı Sistemler Mühendisliği Bölümü'nden mezun oldu. Otomotivin temel konularından güç aktarma organları ile ilgili yazmış olduğu kitap, 2018 yılında yayınlandı. 2019 yılından beri Uşak Üniversitesi'nde öğretim görevlisi olarak çalışmaktadır

\section{Beyanlar:}

E-Posta: beytullah.basegmez@usak.edu.tr

Bu makalede bilimsel araştırma ve yayın etiğine uyulmuştur.

Ömür AKBAYIR deneysel verileri, tren direnci formüllerini toplamış ve sonuçları yorumlamıştır. Beytullah BAŞEĞMEZ verileri ve formülleri kullanarak hesaplamaları ve analizini gerçekleştirmiştir. 